\title{
Meet \& fly: Sustainable transport academics and the elephant in the room
}

\author{
Freke Caseta,b \\ Kobe Boussauwb \\ Tom Stormea \\ a Ghent University, Geography Department - Krijgslaan 281, S8 9000 Ghent, Belgium \\ b Vrije Universiteit Brussel, Cosmopolis Centre for Urban Research VUB - Pleinlaan 2, 1050 Brussels, \\ Belgium
}

To be cited as:

Caset, F., Boussauw, K., \& Storme, T. (2018). Meet \& fly: Sustainable transport academics and the elephant in the room. Journal of Transport Geography, 70, 64-67.

https://doi.org/10.1016/j.jtrangeo.2018.05.020

\section{Introduction}

This viewpoint addresses the discrepancy between our 'normal' academic travel behaviour (flying to meetings all over the planet) and today's hot-topic research agendas in transport studies, including 'sustainable mobility', 'sustainable accessibility', 'resilient and healthy cities', but also 'engaged planning theory and practice' and 'active and responsible citizenship'. As of today, this paradox remains a blind spot within the community of transport academics exploring and advocating sustainable mobility, i.e. the 'sustainable transport academics'. Research agendas and conference themes rarely draw attention to the problem, and transport academics do not seem to organize or openly engage in working towards solutions. We believe this negation of the environmental 'curse' of our hypermobility obstructs immediate and clearcut actions to reduce our carbon footprint, and hampers a shift towards more sustainable academic meeting practices in the long run. We conceptualize a global academic partnership as a promising and necessary route forward, both for science and society.

Two recent developments have stimulated the current viewpoint. First, following US travel restrictions by the Trump administration and Britain's upcoming departure from the EU, the benefits of mobility for science as a whole were lauded once again (e.g. Sugimoto et al., 2017; Wagner and Jonkers, 2017), while the detrimental impacts of the flying it generates are ignored. We believe this to be an untenable situation, one which is ultimately counterproductive for the future of science. Second, one of us participated in a brainstorm workshop organized by a community of sustainable transport academics in Lisbon (July 2017). During the event there was a self-reflexive debate on academic flying as the 'elephant in the room', which arose since two participants had travelled to the venue by modes not taken for granted: by train ( $23 \mathrm{~h}$ ) and by coach $(10 \mathrm{~h})$. Their motives were of environmental nature which led to uneasy shuffling around in chairs.

\section{The paradox in numbers}

The huge environmental impact of academic conferences has been addressed before (see for example Høyer and Naess, 2001; Hischier and Hilty, 2002; Hall, 2007; Lester, 2007; Burke, 2010; Lassen, 2010; Spinellis and Louridas, 2013; Hopkins et al., 2015). Travel to and from these meetings accounts for the largest share of conference-related carbon emissions (Hischier and Hilty, 2002; Bossdorf et al., 2010; Orsi, 2012; Achten et al., 2013). Below, we roughly estimated the travel-related carbon footprint for all 18 participants of the Lisbon brainstorm workshop (see Table 1), by applying the conversion factors provided by DEFRA (2016) ${ }^{1}$.

The results of these back-of-the-envelope calculations ${ }^{2}$ are worrying in a period in which our planet is on the brink of locking in dangerous levels of climate change (Raftery et al., 2017). By attending the workshop, we collectively emitted more than 8 tons of $\mathrm{CO}_{2}$, and over 16 tons of $\mathrm{CO}_{2}$ when including the radiative forcing ${ }^{3}$ effects of the air trips. To put these numbers in perspective; the latter figure equals the annual carbon emissions of 10 Costa Ricans, 4 Norwegians or 1 US citizen. ${ }^{4}$ Table 1 furthermore illustrates how $98 \%$ of all carbon emissions were caused by half of all participants. Even more so, only 2 participants were responsible for $69 \%$ of all carbon emissions. 
Table 1. Estimates of return trip carbon emission for all workshop participants ( $R F=$ radiative forcing).

\begin{tabular}{|c|c|c|c|c|c|c|c|}
\hline & & Country & City & Distance (km) & Category & Conversion factor $\left({ }^{\circ}\right.$ without RF) & $\mathrm{kg} \mathrm{CO} 2\left({ }^{\circ}\right.$ without RF) \\
\hline & 1 & Australia & Melbourne & 17,735 & \multirow[t]{9}{*}{ 'International' } & \multirow[t]{9}{*}{0,18 kg CO2/pp. km $\left({ }^{\circ} 0,09\right)$} & $6065\left({ }^{\circ 3192)}\right.$ \\
\hline & 2 & Australia & Perth & 14,988 & & & $5126\left({ }^{\circ} 2698\right)$ \\
\hline & 3 & The Netherlands & Amsterdam & 1901 & & & $650\left({ }^{\circ} 342\right)$ \\
\hline & 4 & The Netherlands & Amsterdam & 1901 & & & $650\left({ }^{\circ} 342\right)$ \\
\hline & 5 & The Netherlands & Groningen & 2059 & & & $704\left({ }^{\circ} 370\right)$ \\
\hline & 6 & Sweden & Gothenburg & 2619 & & & $896\left({ }^{\circ} 471\right)$ \\
\hline & 7 & Germany & Munich & 2009 & & & $687\left({ }^{\circ} 361\right)$ \\
\hline & 8 & Germany & Munich & 2009 & & & $687\left({ }^{\circ} 361\right)$ \\
\hline \multirow[t]{5}{*}{ AIR } & 9 & United Kingdom & London & 1610 & & & $551\left({ }^{\circ} 290\right)$ \\
\hline & 10 & Belgium & Ghent & 2023 & 'international' & 0,01 kg CO2/pp. km & 41 \\
\hline & 11 & Portugal & Coimbra & 220 & \multirow[t]{4}{*}{ 'national' } & \multirow[t]{4}{*}{ 0,05 kg CO2/pp. km } & 22 \\
\hline & 12 & Portugal & Porto & 330 & & & 33 \\
\hline & 13 & Portugal & Porto & 330 & & & 33 \\
\hline RAIL & 14 & Portugal & Porto & 330 & & & 33 \\
\hline \multirow[t]{3}{*}{ BUS } & 15 & Spain & Granada & 695 & ‘coach' & 0,03 kg CO2/pp. km & 42 \\
\hline & 16 & Portugal & Lisbon & 17 & \multirow[t]{3}{*}{ 'lower medium' } & \multirow[t]{3}{*}{$0,17 \mathrm{~kg} \mathrm{CO} 2 / \mathrm{pp} . \mathrm{km}$} & 3 \\
\hline & 17 & Portugal & Lisbon & 17 & & & 3 \\
\hline \multirow[t]{2}{*}{ CAR } & 18 & Portugal & Lisbon & 17 & & & 6 \\
\hline & & & & & & TOTAL $(\mathrm{kg})$ & $16,232\left({ }^{\circ} 8645\right)$ \\
\hline
\end{tabular}

- Two participants carpooled, therefore these emissions were halved. 
By flying to overseas conferences and meetings, we thus perpetuate the problem we study. Among the first to address this uncomfortable contradiction was Grémillet $(2008,1175)$ who questioned "whether the carbon footprints of ecologists outweigh the environmental benefits of their findings and their lobbying". Besides the field of ecology (see also Fox et al., 2009), this paradox has been addressed within other academes, such as the fields of medicine (Roberts and Godlee, 2007), psychiatry and neuroscience (Young, 2009), biomedical science (Dwyer, 2013) and agricultural economics (Desiere, 2016) and geography (Nevins, 2014). For the case of climate scientists, Attari et al. (2016) even argue that a large personal carbon footprint clearly affects their credibility to the public hence the impact of their advice. It thus seems that "the tool (conference) adopted to share knowledge for improving human wellbeing is actually jeopardizing human wellbeing due to the environmental impact it causes" (Orsi, 2012, 462).

We expect a pioneering role from academics, especially from those occupied with research on sustainable transport and planning, in openly and actively engaging with the problems addressed. Besides the paradox illustrated above, this expectation is supported by the flexibility academics enjoy when it comes to organizing their work and travel (Lassen, 2006). They can, with relative ease, trade off the benefits and costs of trips which may lead to alternative internationalization strategies (Storme et al., 2013). We therefore think that the academic realm can and must take its responsibility and lead by example.

Alas, we do not see this happening within the disciplines occupied with sustainable transport. Research activities addressing potential alternatives or strategies to lessen the dependence on air travel are negligible in the overall corpus of transport research and do not appear within headline conference themes. Scanning some well-used academic web search engines looking for articles dealing with this issue led to a low outcome, with most papers published in journals not directly related to transport issues. ${ }^{5}$ A survey conducted by Banister et al. (2012) for a group of transport geographers furthermore revealed a moderate to low allocation of research priorities to air transport, business travel and telecommunications. Considerate and significant actions to reduce travel carbon emissions on an individual, community or institutional level are rarely taken either.

We can come up with a couple of explanations for the general neglect of the topic in transport research agendas. Self-reflexivity and responsibilization are not very attractive research topics (see also Lassen, 2006) and adequate data sources on (business) air travel are very scarce. But obviously, there's more to it; the mere thought of having to reduce our trips makes us uncomfortable already.

\section{Heads in the clouds}

It seems to be more convenient to sit by and watch the aviation industry solve the problem. Popular media recurrently report about sustainable aircraft technology and new aircraft prototypes. ${ }^{6}$ These are grist to the mill of airline companies, who have every interest in feeding a discourse in which an entirely clean manner of operation is just a couple of years away. We believe technological improvements for long-distance travel won't likely bring meaningful solutions for decades to come and refer to this as the 'technological hoax'. Aviation innovation will in reality prove too little, too late, especially if the expected growth in air travel demand is taken into account.

Take electric flying, which in fact comes down to flying with a 'more electric aircraft' and relies on fossil fuel 'for propulsion only' (Wheeler, 2016). Another back-of-the-envelope calculation makes clear that fast flying with a large electric aircraft is indeed a wish dream that may not even be compatible with the basic laws of physics. To store the electrical energy equivalent of the fuel tank of an Airbus A380 $\left(320 \mathrm{~m}^{3}\right)$, we would need about 22,000 tons of currently available commercial batteries, ${ }^{7}$ representing about 38 times the maximum take-off weight of such an aircraft. The most promising electrical alternative would be a not-that-small on-board nuclear reactor, a rather frightening idea that was indeed on the drawing tables of military aircraft designers during the Cold War (Lange, 1976). Similar arguments can be made for biofuel propulsion. Although it is technically possible to propel an aircraft by means of biofuel, the scale on which energy crops should be grown is of such a nature that it would put tremendous pressure, not only on food production, but also on biodiversity at a global scale. A last back-of-theenvelope calculation ${ }^{8}$ indicates that a switch from the current worldwide consumption of kerosene fuel (approximately 2 billion barrels per year) to biofuels would necessitate an expansion of the global agricultural area by around $7 \%$.

And even if technological breakthroughs are going to be significant and at relatively short notice, they most likely will not reduce the absolute amount of emission from aviation, due to the huge demand in 
growth forecasted, including growth from those nations where the sector is considered to be mature (Chapman, 2007; Bows and Anderson, 2007; Grote et al., 2014). Globally, air travel is soaring almost exponentially (European Union, 2015; World Bank, 2017). By 2100, the world's population is expected to consume nine times more distance than in 2015 and the average distance covered per trip is set to double (Peeters, 2017). Growth in travel demand seems to outweigh all efforts within the sector to reduce its climate impact (Banister et al., 2012; Sims et al., 2014; Peeters, 2017). As a corollary, for future commercial aviation, to which speed and large capacities are vital, a significant electric, biofuel or fuel cell powered future remains far-off, and these 'technology myths' may result in inaction which continues to delay much needed progress in climate policy for aviation (Peeters et al., 2016). The inconvenient truth about flying is simply that there is no one-on-one alternative for kerosene combustion in aviation.

We seem to live in a finite time window in which long-haul travel is a privilege we all-too-easily take for granted (Nevins, 2014). It would be naïve to assume we can continue 'as is'. Yet no academic is really looking forward to cut back on her or his own travels. Part of it has to do with the fact that regular (air) travel provides a break from everyday routines and allows mixing work and play (see Gustafson, 2006). More important however, is that behind many travels lie important (and somewhat invisible) social mechanisms (Urry, 2007). Travel fulfils meeting expectations and obligations between members of transnational academic networks (Storme, 2014). The majority of the trips undertaken by academics is to meet and re-meet each other in the conference circuit and/or through circular mechanisms of invited speeches and lectures. We recognize that today, (rich and) important social goods are exchanged through repeated formal and informal face-to-face meetings (Storme et al., 2018). These meetings lead to the latest insights, future collaboration and publication opportunities, new job prospects, etc. Not being able to travel is associated with a fear of missing out. The importance of engagement in transnational networks is reflected in the 'internationalization'-discourses of academic institutions, in which 'brain circulation' is considered vital for early-career scientists and therefore stimulated by funding agencies (Ackers 2008). In doing so, mobility is implicitly stimulated and there is hardly any room to debate its environmentally alarming character (Glover et al., 2017).

\section{The route forward}

The real challenge is therefore to reduce significant amounts of kilometres flown, while retaining high levels of international collaboration, quality and productivity. We believe this is possible by self-imposing an academic emission ceiling. Although this idea may seem radical, it is inspired by existing sectoral and (inter)national carbon cap schemes (McAllister, 2014). We imagine a transnational academic partnership in which all research institutes in the world commit themselves to reducing the emissions covered by their staff by, for example, $5 \%$ each year (a rate in line with the $40 \%$ reduction target of Europe by 2030 within the Paris agreement). This way, academia could firmly grow towards a lowcarbon future without precluding scientific progress. We believe the least useful as well as the most easily substitutable meetings would immediately be avoided, hence a natural break to the growth of mainly the less useful trips would occur.

The implementation and coordination of such a scheme is not self-evident. In first instance, it seems logical to assign such a mandate to a supranational organization. UN agencies would be obvious candidates for such a task, and UNESCO in particular, since it deals with the education and research sectors. However, a breakthrough seems more realistic on the basis of a pre-existing breeding ground, which could consist of an academic partnership of voluntarily joined research groups that commit themselves to closely monitor their own air travel related emissions and indeed reduce them by $5 \%$ each year, in this way building the momentum required for further, supranational action. The system we propose would start from a linear reduction, based on the current proportions in terms of air travel consumption, but would leave room for social corrections within a cap-and-trade system (Stavins, 2003). Research groups at remote institutes in the Australian continent, or those doing research in regions far from their home base, would also in the future be allowed to fly more than average, albeit within an emission budget that would be declining for them as well. Social corrections would apply to researchers working in countries of the Global South who, on the basis of a faster than average declining air travel budget in the countries of the Global North, might still count on a temporarily growth of their air travel budget.

Obviously, such a new academic modus operandi would lead to substantial changes in meeting practices. Part of an operational response to a self-imposed emission ceiling implies optimizing every single aspect of potential face-to-face meetings in terms of environmental sustainability (e.g. purpose/need, travel mode, meeting location). It will also involve reducing the frequency of face-to-face 
meetings with far-away colleagues (Philippe, 2008), combining multiple purposes at the destination (work-work, but also work-play), and implementing a surcharge on conference fees. A more considerate action however, includes the incorporation of geography into the meeting location selection process (Ponette-González and Byrnes, 2011), by centralizing meeting locations between attendees on a regional scale, and by decentralizing large international conferences over multiple sites that are connected via virtual communication technologies ${ }^{9}$ (Hischier and Hilty, 2002; Ponette-González and Byrnes, 2011; Coroama et al., 2011; Orsi, 2012; Stroud and Feeley, 2015). We believe the 'multiple-site paradigm' may hold an important key to a proper adaptation strategy, as it allows a considerable cut of carbon emissions, without precluding the physical meeting of scientists. Some scientific organizations have already commenced experimenting with this new conference format and satisfaction of participants proved overwhelmingly positive. ${ }^{10}$

A full range of alternatives and actors (ranging from conference organizers and funding agencies to individual academics and the communities in which they function) will thus need to be mobilised and, although some of these measures may sound commonsensical, it is paramount to consider them part of this new academic modus operandi, which is serving the ultimate goal of sticking to the declining emission ceiling while maintaining current levels of academic quality and productivity. After all, without an emission ceiling, stand-alone measures aimed at reducing emissions will likely be compensated through a natural rebound effect (Saunders, 1992). In anticipation of a new academic modus operandi, we should not underestimate the value of action by individual academic communities, who have the power and freedom to strategize, to organize effective action and to lobby with conferences and institutes. We believe sustainable transport academics in particular, could lead the charge against 'business as usual' by demonstrating a radically different way of doing business (after Burke, 2010). Or, as Bonnett (2006, p. 230) puts it: "It is about a shift in culture. It is a hard thing for a geography academic to say, but the glory days of guilt-free and gleeful world winging are gone. Travel is no longer an escape. It is a responsibility".

References

Achten et al., 2013

W.M.J. Achten, J. Almeida, B. Muys

Carbon footprint of science: more than flying

Ecol. Indic., 34 (2013), pp. 352-355

Ackers, 2008

L. Ackers

Internationalisation, Mobility and Metrics: A New Form of Indirect Discrimination?

Minerva, 46 (4) (2008), pp. 411-435 https://doi.org/10.1007/s11024-008-9110-2

Aguiléra et al., 2012

A. Aguiléra, C. Guillot, A. Rallet

Mobile ICTs and physical mobility: review and research agenda

Transp. Res. A, 46 (2012), pp. 664-672

Attari et al., 2016

S.Z. Attari, D.H. Krantz, E.U. Weber

Statements about climate researchers' carbon footprints affect their credibility and the impact of their advice

Clim. Chang., 138 (1-2) (2016), pp. 325-338

Banister et al., 2012

D. Banister, T. Schwanen, J. Anable 
Introduction to the special section on theoretical perspectives on climate change mitigation in transport

J. Transp. Geogr., 24 (2012), pp. 467-470

Bonnett, 2006

A. Bonnett

The need for sustainable conferences

Area, 38 (2006), pp. 229-230

Bossdorf et al., 2010

O. Bossdorf, M. Parepa, M. Fischer

Climate-neutral ecology conferences: just do it!

Trends Ecol. Evol., 25 (2) (2010), p. 61

Bows and Anderson, 2007

A. Bows, K.L. Anderson

Policy clash: can projected aviation growth be reconciled with the UK Government's $60 \%$ carbon-reduction target?

Transp. Policy, 14 (2) (2007), pp. 103-110

Burke, 2010

I.C. Burke

Travel trade-offs for scientists

Science, 330 (2010), p. 1476

Chapman, 2007

L. Chapman

Transport and climate change: a review

J. Transp. Geogr., 15 (5) (2007), pp. 354-367

Coroama et al., 2011

V. Coroama, L. Hilty, M. Birtel

Effects of internet-based multiple-site conferences on greenhouse gas emissions

Telematics Inform., 29 (4) (2011), pp. 362-374

DEFRA, 2016

DEFRA

2016 Government GHG Conversion Factors for Company Reporting: Methodology Paper for Emission Factors

(2016)

Desiere, 2016

S. Desiere 
The carbon footprint of academic conferences: evidence from the $14^{\text {th }}$ EAAE congress in Slovenia

EuroChoices, 15 (2) (2016), pp. 56-61

Dwyer, 2013

J. Dwyer

Flying to ethics conferences: climate change and moral responsiveness

Int. J. Fem. Approaches Bioeth., 6 (1) (2013), pp. 1-18

European Union, 2015

European Union

Emission reduction target for international aviation and shipping

, Study for the ENVI Committee,

(2015) http://www.europarl.europa.eu/RegData/etudes/STUD/2015/569964/IPOL_STU(2015)569964 EN.pdf

Fox et al., 2009

H.E. Fox, P. Kareiva, B. Silliman, J. Hitt, D.A. Lytle, B.S. Halpern, C.V. Hawkes, J. Lawler, M. Neel, J.D. Olden, M.A. Schlaepfer, K. Smith, H. Tallis

Why do we fly? Ecologists' sins of emission

Front. Ecol. Environ., 7 (6) (2009), pp. 294-296

Glover et al., 2017

A. Glover, Y. Strengers, T. Lewis

The unsustainability of academic aeromobility in Australian universities

Sustain. For., 13 (1) (2017), pp. 1-12

Grémillet, 2008

D. Grémillet

Paradox of flying to meetings to protect the environment

Nature, 455 (2008), p. 1175

Grote et al., 2014

M. Grote, I. Williams, J. Preston

Direct carbon dioxide emissions from civil aircraft

Atmos. Environ., 95 (2014), pp. 214-224

Gustafson, 2006

P. Gustafson

Work-related travel, gender and family obligations

Work Employ. Soc., 20 (3) (2006), pp. 513-530

Hall, 2007

E. Hall 
Alternative futures for academic conferences: a response to Bonnett

Area, 39 (1) (2007), pp. 125-129

Hischier and Hilty, 2002

R. Hischier, L. Hilty

Environmental impacts of an international conference

Environ. Impact Assess. Rev., 22 (2002), pp. 543-557

Hopkins et al., 2015

D. Hopkins, J. Higham, S. Tapp, T. Duncan

Academic mobility in the Anthropocene era: a comparative study of university policy at three New Zealand institutions

J. Sustain. Tour., 24 (2015), pp. 376-397

Høyer and Naess, 2001

K.G. Høyer, P. Naess

Conference tourism: a problem for the environment, as well as for research?

J. Sustain. Tour., 9 (6) (2001), pp. 451-470

Lange, 1976

R.H. Lange

Design concepts for future cargo aircraft

J. Aircr., 13 (6) (1976), pp. 385-392

Lassen, 2006

C. Lassen

Aeromobility and work

Environ. Plan. A, 38 (2006), pp. 301-312

Lassen, 2010

C. Lassen

Environmentalist in business class: an analysis of air travel and environmental attitude

Transp. Rev., 30 (6) (2010), pp. 733-751

Lassen et al., 2006

C. Lassen, B.T. Laugen, P. Naess

Virtual mobility and organizational reality - a note on the mobility needs in knowledge organisations

Transp. Res. D, 11 (2006), pp. 459-463

Lester, 2007

B. Lester

Greening the meeting 
Science, 318 (Oct. 5) (2007), pp. 36-38

McAllister, 2014

L.K. McAllister

Cap and trade

M.B. Gerrard, J. Freeman (Eds.), Global Climate Change and U.S. Law (2nd Edition, Pp. 341-373), American Bar Association (2014)

Milmo, 2008

D. Milmo

'Biofuel Flying will Take off in Three Years, Says Boeing', The Guardian

https://www.theguardian.com/environment/2008/oct/27/biofuel-boeing-carbon-offsetting (2008)

Nevins, 2014

J. Nevins

Academic jet-setting in a time of climate destabilization: ecological privilege and professional geographic travel

Prof. Geogr., 66 (2) (2014), pp. 289-310

Orsi, 2012

F. Orsi

Cutting the carbon emission of international conferences: is decentralization an option?

J. Transp. Geogr., 24 (2012), pp. 462-466

Peeters, 2017

P.M. Peeters

Tourism's Impact on Climate Change and its Mitigation Challenges. Doctoral Dissertation

Technische Universiteit Delft (2017)

Peeters et al., 2016

P.M. Peeters, J. Higham, D. Kutzner, S. Cohen, S. Gössling

Are technology myths stalling aviation climate policy?

Transp. Res. Part D: Transp. Environ., 44 (2016), pp. 30-42

Philippe, 2008

H. Philippe

Less is more: decreasing the number of scientific conferences to promote economic degrowth

Trends Genet., 24 (2008), pp. 265-267

Ponette-González and Byrnes, 2011

A. Ponette-González, J.E. Byrnes

Sustainable science? Reducing the carbon impact of scientific mega-meetings

Ethnobiol. Lett., 2 (2011), pp. 65-71 
Poom et al., 2017

A. Poom, K. Orru, R. Ahas

The carbon footprint of business travel in the knowledge-intensive service sector

Transp. Res. D, 50 (2017), pp. 292-304

Raftery et al., 2017

A.E. Raftery, A. Zimmer, D.M.W. Frierson, R. Startz, P. Liu

Less than $2^{\circ} \mathrm{C}$ warming by 2100 unlikely

Nat. Clim. Chang. (2017) https://doi.org/10.1038/nclimate3352

Roberts and Godlee, 2007

I. Roberts, F. Godlee

Reducing the carbon footprint of medical conferences

Br. Med. J., 334 (2007), pp. 324-325

Rosen, 2017

E. Rosen

As billions more fly, here's how aviation could evolve

Natl. Geogr. (2017) https://www.nationalgeographic.com/environment/urban-

expeditions/transportation/air-travel-fuel-emissions-environment/

Saunders, 1992

H.D. Saunders

The Khazzoom-Brookes postulate and neoclassical growth

Energy J., 13 (4) (1992), pp. 131-148

Sims et al., 2014

R. Sims, R. Schaeffer, F. Creutzig, X. Cruz-Nu nez, M. D'agosto, D. Dimitriu, ... G. Tiwari

Transport

O. Edenhofer, R. Pichs-Madruga, Y. Sokona, E. Farahani, S. Kadner, K. Seyboth, A. Adler, I. Baum, S. Brunner, P. Eickemeier, B. Kriemann, J. Savolainen, S. Schlömer, C. Von Stechow, T. Zwickel, J.C. Minx (Eds.), Climate change 2014: Mitigation of climate change. Contribution of Working Group III to the Fifth Assessment Report of the Intergovernmental Panel on Climate Change (Chapter 8, Pp. 599-670), Cambridge University Press, Cambridge (2014)

Spinellis and Louridas, 2013

D. Spinellis, P. Louridas

The carbon footprint of conference papers

PLOS ONE, 8 (6) (2013)

Stavins, 2003

R.N. Stavins

Experience with market-based environmental policy instruments 
in: K.G. Mäler, J.R. Vincent (Eds.), Handbook of Environmental Economics, Vol. 1, Elsevier Science \& Technology, Amsterdam (2003), pp. 355-435

Storme, 2014

T. Storme

Exploring a Small World: Motivations and Obligations for Academic Travel in a Flemish

Context. Ghent University. PhD Dissertation

Faculty of Sciences, Ghent, Belgium (2014)

Storme et al., 2013

T. Storme, J.V. Beaverstock, B. Derudder, J.R. Faulconbridge, F. Witlox

How to cope with mobility expectations in academia: individual travel strategies of tenured academics at Ghent University, Flanders

Res. Transp. Bus. Manag., 9 (2013), pp. 12-20

Storme et al., 2018

T. Storme, J.R. Faulconbridge, J.V. Beaverstock, B. Derudder, F. Witlox

Mobility and professional networks in academia: an exploration of the obligations of presence

Mobilities, 12 (3) (2018), pp. 405-424

Stroud and Feeley, 2015

J.T. Stroud, K.J. Feeley

Responsible academia: optimizing conference locations to minimize greenhouse gas emissions

Ecography, 38 (4) (2015), pp. 402-404

Sugimoto et al., 2017

C.R. Sugimoto, N. Robinson-Garcia, D.S. Murray, A. Yegros-Yegros, R. Costas, V. Larivière

Scientists have most impact when they're free to move

Nature News, 550 (7674) (2017), p. 29

Tan, 2018

J.L. Tan

All-Electric Flying Cars get Closer to Reality

http://www.eco-business.com/news/all-electric-flying-cars-get-closer-to-reality/ (2018)

Urry, 2007

J. Urry

Mobilities

Polity Press, Cambridge (2007)

Wagner and Jonkers, 2017

C.S. Wagner, K. Jonkers

Open countries have strong science 
Nature, 550 (2017), pp. 32-33 https://doi.org/10.1038/550032a

Wheeler, 2016

P. Wheeler

Technology for the more and all electric aircraft of the future

, Presented at the IEEE International Conference on Automatica (ICA-ACCA), IEEE, Curico, Chile (2016)

World Bank, 2017

World Bank

Air Transport, Passengers Carried

Retrieved from: https://data.worldbank.org/indicator/IS.AIR.PSGR (2017)

Young, 2009

S.N. Young

Rethinking scientific meetings: an imperative in an era of climate change

J. Psychiatry Neurosci., 34 (2009), pp. 341-342

Among all possible guidelines we chose to use the DEFRA report due to its solid methodological approach in which key data sources and assumptions to define the factors are transparently communicated and regularly updated. Some methodological drawbacks however need mentioning in light of our workshop case. As for the train trips, the DEFRA conversion factors do not include passenger-km weighted averages for the emission factors for Spain and Portugal (only UK and Eurostar routes running through the UK, France and Belgium are considered). A similar remark holds for the 'coach' value as emission factors are based on figures from the majority of scheduled coach services in the UK. Lastly, as for the air trips, the 'international' category figures were used for all flights, although according to DEFRA one trip would classify as 'short-haul' since it departs from a UK-based airport. For reasons of clarity and because both factors don't vary much, we chose to classify all flights as 'international'. For all trips, the 'average passenger' numbers were used.

2

Of course this empirical exercise only informs us about those who actually attended the event, and does not reveal the individual choices and options considered. It is after all possible that the brainstorm workshop was the one event per year that some of the participants allowed themselves to fly to. Ideally therefore, analysis of emissions should start from the perspective of individual academics and the individual, social and institutional factors shaping their mobility decisions.

The total climate impact of aviation is larger than its $\mathrm{CO}_{2}$ emissions (European Union, 2015; DEFRA, 2016). Additional warming effects are caused by emissions of $\mathrm{NO}_{x}$ and $\mathrm{SO}_{2}$ into the upper troposphere, the formation of contrails, and the seeding of cirrus clouds with aerosols from fuel combustion. As there is still much uncertainty about the extent of some of these effects, there is no suitable climatic metric available that could be used to express the full climate impact of aviation. However, a 'multiplier' to account for these non- $\mathrm{CO}_{2}$ effects is usually proposed. In line with DEFRA (2016) we adopted the 1,9 central estimate.

Averages per country. Data from the World Bank (https://data.worldbank.org/indicator/EN.ATM.CO2E.PC)

Google scholar, Scopus and ISI Web of Science were consulted and screened for different combinations of the following keywords: "conferences", "sustainable", "aviation", "climate 
change" and "academics". The articles specifically focusing on the environmental impact of academic flying were retained, and are all included in the reference list of the current paper.

See for example Milmo (2008), Rosen (2017) and Tan (2018).

Assuming the use of Li-ion batteries as applied in the Tesla S all electric vehicle, with an energy density of $1.4 \mathrm{Wh} / \mathrm{kg}$.

8

Calculated on the basis of the energy content of ethanol extracted from cane sugar at a rate of $84 \mathrm{GJ} / \mathrm{ha}$.

Although virtual communication technologies have in the past been considered promising substitutes for physical travel, their relationships have proved ambiguous at best. In reality, ICTs can also be seen as complementary to physical travel, can also generate more physical travel and can be quite neutral towards physical travel (see Aguiléra et al., 2012). As Poom et al. (2017, pp. 293-294) put it: "ICT can in fact stimulate further travel by increasing the size of one's social network and the intensity of the communications between members of the network, thereby creating the need for additional face-to-face meetings (...) In addition, the use of ICT is itself not entirely environmentally friendly due to its use of energy, the short life-span of many ICT devices, and other environmental impacts of production". In light of the academic partnership proposed in this viewpoint, we call for more experimentation with virtual meeting practices that might create momentum for the tool builders to optimize it so that they will prove to be more effective than physical travel practices. Furthermore, as Lassen et al. (2006) indicated, there is a connection between knowledge of virtual communication technology and the willingness to use it.

For example, the two-day Global Arts and Psychology Seminar was hosted in 2017 over five hubs (Boston, La Plata, Sheffield, Graz and Sydney), mixing in-person and virtual conferencing as a pilot run for a larger professional conference in 2018. Each hub transmitted its local presentations live to the cloud and all other hubs could choose which presentations to include in their virtual program, either live or with a time delay. Another example is the World Resource Forum conference which was organized in 2009 as a two-site event, taking place in Japan and Switzerland simultaneously (see Coroama et al., 2011). The results showed a significant reduction in travel-related emissions, along with an overwhelmingly positive experience of the participants as revealed by a survey. 